\title{
Amine substitution into sulfuric acid - ammonia clusters
}

\author{
O. Kupiainen ${ }^{1}$, I. K. Ortega ${ }^{1}$, T. Kurtén ${ }^{2}$, and H. Vehkamäki ${ }^{1}$ \\ ${ }^{1}$ Division of Atmospheric Sciences, Department of Physics, P.O. Box 64, 00014 University of Helsinki, Finland \\ ${ }^{2}$ Laboratory of Physical Chemistry, Department of Chemistry, P.O. Box 55, 00014 University of Helsinki, Finland
}

Correspondence to: O. Kupiainen (oona.kupiainen@ helsinki.fi)

Received: 15 September 2011 - Published in Atmos. Chem. Phys. Discuss.: 18 November 2011

Revised: 23 March 2012 - Accepted: 30 March 2012 - Published: 16 April 2012

\begin{abstract}
The substitution of ammonia by dimethylamine in sulfuric acid - ammonia - dimethylamine clusters was studied using a collision and evaporation dynamics model. Quantum chemical formation free energies were computed using B3LYP/CBSB7 for geometries and frequencies and RI-CC2/aug-cc-pV(T+d)Z for electronic energies. We first demonstrate the good performance of our method by a comparison with an experimental study investigating base substitution in positively charged clusters, and then continue by simulating base exchange in neutral clusters, which cannot be measured directly. Collisions of a dimethylamine molecule with an ammonia containing positively charged cluster result in the instantaneous evaporation of an ammonia molecule, while the dimethylamine molecule remains in the cluster. According to our simulations, a similar base exchange can take place in neutral clusters, although the overall process is more complicated. Neutral sulfuric acid - ammonia clusters are significantly less stable than their positively charged counterparts, resulting in a competition between cluster evaporation and base exchange.
\end{abstract}

\section{Introduction}

Atmospheric aerosols are known to affect the climate by absorbing and scattering radiation and acting as cloud condensation nuclei. According to recent estimates (Merikanto et al., 2009) $20-80 \%$ of the aerosol particles are formed in the atmosphere by gas-to-particle nucleation. There remains, however, much uncertainty related to their actual birth-mechanism and composition. Consequently, aerosol forcing forms the largest uncertainty in global climate modeling.
New-particle formation rates have been observed to correlate strongly with sulfuric acid concentrations in a wide range of conditions (Sihto et al., 2006; Kuang et al., 2008), suggesting that sulfuric acid would be involved in the first steps of nucleation. However, particle formation can not be explained by homogeneous nucleation of sulfuric acid and water alone. Instead, some third compound is needed to stabilize the small sulfuric acid clusters and enable them to grow into particles. Bases such as ammonia that are present in the atmosphere at relevantly high concentrations have been proposed as good candidates since they bind strongly with sulfuric acid (Torpo et al., 2007; Nadykto and Yu, 2007; Ortega et al., 2008). Recent results at the CLOUD experiment in CERN suggest that ammonia does not enhance the growth of sulfuric acid clusters enough to account for the nucleation rates observed in the boundary layer (Kirkby et al., 2011). However, it has been seen in earlier modeling studies that amines stabilize sulfuric acid clusters significantly more than ammonia (Kurtén et al., 2008; Loukonen et al., 2010), although different quantum-chemistry methods give somewhat different results concerning the magnitude of the stability difference (Nadykto et al., 2011; Kurtén, 2011).

Once the initial sulfuric-acid-containing clusters have been formed, their growth is mainly due to various organic vapors (O'Dowd et al., 2002a; Shantz et al., 2003; Maria et al., 2004). Organic compounds can also take part in the initial steps of sulfuric acid cluster formation (Zhang et al., 2004; Metzger et al., 2010; Nadykto and Yu, 2007; Xu et al., 2010). In coastal areas nucleation can also be driven by iodine compounds (O'Dowd et al., 2002b).

Although aerosol measurement techniques have been developing rapidly (Kulmala et al., 2007; Manninen et al., 2009; Junninen et al., 2010), the ability to detect and 
characterize even charged sub $3 \mathrm{~nm}$ clusters remains limited. Furthermore, neutral clusters can only be detected by charging them, but the complex chemistry of the charging process complicates the interpretation of such measurements (Kurtén et al., 2011). On the other hand, neutral pathways account for $90 \%$ of atmospheric new particle formation (Kulmala et al., 2007), and understanding neutral cluster formation is, therefore, a key issue.

At present, the most accurate way to study small neutral clusters is by quantum chemistry. It can, in principle, be applied to any system, and requires no experimental input data. The methods can first be tested against ionic cluster measurements, and then used for neutral clusters to gain information that could not be obtained experimentally.

In a recent experimental study, Bzdek et al. (2010a) studied base substitution in small sulfuric acid - ammonia dimethylamine (DMA) clusters. In this contribution, we present a quantum chemistry-based study of the same system, and show that our method is able to reproduce the experimental results. Further, we extend our discussion to base substitution in electrically neutral clusters and point out some important differences.

\section{Theory and computational methods}

\subsection{Quantum chemistry details}

Calculations were performed using a multi-step method presented by Ortega et al. (2012). The method is briefly described here, and a more detailed account of the effect of the basis set and level of theory can be found in Ortega et al. (2012).

For each cluster, a sample of around 5 to 20 initial guess geometries was taken from earlier studies when possible, or constructed using chemical intuition and pre-optimized with molecular dynamics using the SPARTAN program (Wave function, 2006). It has to be noted that as the size of the cluster grows, the number of conformers grows, so for large clusters the existence of a cluster more stable that those that we have found cannot be ruled out.

The initial guess geometries were optimized with the Gaussian09 program (Frisch et al., 2009) using the B3LYP hybrid functional (Becke, 1993) and a CBSB7 basis set (Montgomery et al., 1999), which were found to be the best compromise between accuracy and computational effort in a previous study on molecular clusters (Ortega et al., 2012). This basis set is used in the optimization and frequency part of the CBS-QB3 method (Montgomery et al., 1999), which is very accurate but unfortunately computationally too heavy for our large clusters. We did not, however, use the scaling factors associated to the CBSB7 basis, since they are optimized for intramolecular covalent bonds and overestimate the strength of weaker intermolecular bonds. Vibrational and rotational contributions to the Gibbs free energy were calculated within the standard rigid-rotor harmonicoscillator ideal gas (RRHO) approximation (see e.g. Ortega et al., 2008) using the Gaussian09 program.

For the most stable configurations, we computed a more accurate value of the electronic energy with the TURBOMOLE program (Ahlrichs et al., 1989) using the RI-CC2 method (Hättig and Weigend, 2000) and an aug-cc-pV(T+d)Z basis set (Dunning et al., 2001). According to previous basis set extrapolation results (Kurtén et al., 2007a,b), a larger basis set would improve the results relatively little and this choice should be adequate for our purposes.

\subsection{Cluster dynamics}

The time-dependence of cluster concentrations is governed by the birth-death equations (see e.g. Vehkamäki, 2006; Kulmala, 2010)

$$
\begin{aligned}
& \frac{\mathrm{d} C\left(\left\{N_{1}, N_{2}, \ldots, N_{n}\right\}\right)}{\mathrm{d} t}= \\
& \sum_{j=1}^{n}\left[C_{j} \times C\left(\left\{N_{1}, \ldots, N_{j}-1, \ldots, N_{n}\right\}\right)\right. \\
& \times \beta_{j}\left(\left\{N_{1}, \ldots, N_{j}-1, \ldots, N_{n}\right\}\right) \\
& -C_{j} \times C\left(\left\{N_{1}, \ldots, N_{j}, \ldots, N_{n}\right\}\right) \times \beta_{j}\left(\left\{N_{1}, \ldots, N_{j}, \ldots, N_{n}\right\}\right) \\
& -C\left(\left\{N_{1}, \ldots, N_{j}, \ldots, N_{n}\right\}\right) \times \gamma_{j}\left(\left\{N_{1}, \ldots, N_{j}, \ldots, N_{n}\right\}\right) \\
& \left.+C\left(\left\{N_{1}, \ldots, N_{j}+1, \ldots, N_{n}\right\}\right) \times \gamma_{j}\left(\left\{N_{1}, \ldots, N_{j}+1, \ldots, N_{n}\right\}\right)\right],
\end{aligned}
$$

where $C\left(\left\{N_{1}, \ldots, N_{n}\right\}\right)$ is the concentration of clusters with $N_{1}$ molecules of type 1 etc., $\beta_{j}\left(\left\{N_{1}, \ldots, N_{n}\right\}\right)$ is the collision coefficient of these clusters with molecules of type $j$, $\gamma_{j}\left(\left\{N_{1}, \ldots, N_{n}\right\}\right)$ is the evaporation rate of molecules $j$ from such a cluster and $C_{j}$ is the concentration of molecules $j$. Here we have assumed that only single molecules can stick to clusters and evaporate from them, and processes involving more than one cluster can be neglected.

For neutral processes, we have used the collision frequency derived from kinetic gas theory,

$\beta_{j}\left(\left\{N_{i}\right\}\right)=(8 \pi k T)^{1 / 2}\left(\frac{1}{m\left(\left\{N_{i}\right\}\right)}+\frac{1}{m_{j}}\right)^{1 / 2}\left(r\left(\left\{N_{i}\right\}\right)+r_{j}\right)^{2}$,

where $m\left(\left\{N_{i}\right\}\right), m_{j}, r\left(\left\{N_{i}\right\}\right)$ and $r_{j}$ are the masses and radii of the cluster and the molecule, respectively, $k$ is the Boltzmann constant and $T$ is the temperature. For ionic clusters, we have calculated the collision frequency as proposed by $\mathrm{Su}$ and Bowers (1973),

$$
\begin{gathered}
\beta_{j}\left(\left\{N_{i}\right\}\right)=2 \pi Z e\left(\frac{1}{m\left(\left\{N_{i}\right\}\right)}+\frac{1}{m_{j}}\right)^{1 / 2} \\
\times\left[\alpha_{j}^{1 / 2}+c \mu_{j}\left(\frac{2}{\pi k T}\right)^{1 / 2}\right] .
\end{gathered}
$$

The first term in the square brackets corresponds to the Langevin collision rate, which depends on the polarizability 
$\alpha_{j}$ of the colliding molecule. The second term is the collision frequency of a polar molecule (dipole moment $\mu_{j}$ ) with an ion, calculated assuming that the dipole moment is constantly pointing in the lowest energy direction, and scaled by a numerical factor $c \in[0,1]$. (The value $c=1$ would correspond to the dipole being perfectly locked towards the ion, whereas $c=0$ would mean that the rotation of the molecule is unaffected by the electric field and it behaves effectively as a non-polar molecule.) We have used the value $c=0.15$ suggested by Su and Bowers (1973). $Z \times e$ is the charge of the cluster.

The evaporation rate of molecules $j$ from a cluster is

$$
\begin{aligned}
& \gamma_{j}\left(\left\{N_{1}, \ldots, N_{n}\right\}\right)=\frac{P_{0}}{k T} \beta_{j}\left(\left\{N_{1}, \ldots, N_{j}-1, \ldots, N_{n}\right\}\right) \\
& \times \exp \left[\frac{\Delta G\left(\left\{N_{1}, \ldots, N_{n}\right\}\right)-\Delta G\left(\left\{N_{1}, \ldots, N_{j}-1, \ldots, N_{n}\right\}\right)}{k T}\right],
\end{aligned}
$$

where $\Delta G$ are the Gibbs free energies of formation of clusters from monomers at some reference pressure $P_{0}$ (Ortega et al., 2012).

The radii used in the neutral collision coefficients were calculated from bulk liquid densities assuming spherical droplets and ideal mixing. The collision rates obtained with this simplified approach are estimated to be accurate to within a factor of 2 or 3 (Ortega et al., 2012). In the case of charged clusters, we used experimental gas-phase values for the dipole moments and polarizabilities, except for the sulfuric acid polarizability for which an experimental value was (to our knowledge) not available, we used a computational estimate. The values are listed in Table 1. For calculating the evaporation rates, we used the Gibbs free energies from quantum chemistry.

In our kinetic model we have assumed for all collisions a sticking factor of unity, i.e. that the colliding molecule sticks to the cluster irrespective of the collision geometry and kinetic energy. The effect of energy non-accommodation to sticking factors is likely to be small for the clusters studied here, as they are both strongly bound and have several tens of vibrational degrees of freedom (Kurtén et al., 2010). The experimental results by Bzdek et al. (2010a,b) also suggest that sticking coefficients are close to unity.

\section{Results}

The formation free energies of the clusters are given in Table 2 for charged clusters and in Table 3 for neutral mixedbase clusters. Results for pure sulfuric acid, sulfuric acid ammonia and sulfuric acid - DMA clusters have been presented previously by Ortega et al. (2012). For simplicity, the cluster names are written in terms of sulfuric acid (SA), ammonia (Am) and DMA molecules, and the extra proton attached to one base molecule and giving the overall positive charge is not included explicitly. In many cases, one or even two protons have also been transfered from each acid
Table 1. Properties of the modeled species.

\begin{tabular}{lccc}
\hline & $\begin{array}{c}\text { Bulk density } \\
\left(\mathrm{kg} \mathrm{m}^{-3}\right)\end{array}$ & $\begin{array}{c}\text { Polarizability } \\
\left(\AA^{3}\right)\end{array}$ & $\begin{array}{c}\text { Dipole } \\
\text { moment (D) }\end{array}$ \\
\hline Sulfuric acid & $1830^{\mathrm{a}}$ & $6.2^{\mathrm{b}}$ & $2.96^{\mathrm{c}}$ \\
Ammonia & $696^{\mathrm{a}}$ & $2.81^{\mathrm{a}}$ & $1.47^{\mathrm{a}}$ \\
Dimethylamine & $680^{\mathrm{a}}$ & $6.37^{\mathrm{a}}$ & $1.01^{\mathrm{a}}$ \\
\hline
\end{tabular}

${ }^{\mathrm{a}}$ Lide (2010), ${ }^{\mathrm{b}}$ Nadykto and Yu (2003), ${ }^{\mathrm{c}}$ Sedo et al. (2008).

molecule to the bases. The coordinates of the most stable conformer of each cluster are given in the Supplement.

In addition to the ground state electronic energy $E_{\text {elec}}$, we present the Gibbs free energy $G$ and the enthalpy $H$ at $T=298 \mathrm{~K}$ and $P=1 \mathrm{~atm}$. The formation free energies are calculated relative to neutral molecules, except for one positively charged $\left(\mathrm{CH}_{3}\right)_{2} \mathrm{NH}_{2}^{+}$ion in case of positive clusters, or one positively charged $\mathrm{NH}_{4}^{+}$ion for charged sulfuric acid - ammonia clusters with no DMA. In order to calculate energy differences between charged clusters with and without DMA, the reaction energy of the proton transfer $\mathrm{NH}_{4}^{+}+\left(\mathrm{CH}_{3}\right)_{2} \mathrm{NH} \rightarrow \mathrm{NH}_{3}+\left(\mathrm{CH}_{3}\right)_{2} \mathrm{NH}_{2}^{+}\left(\Delta^{\mathrm{pt}} E_{\text {elec }}=\right.$ $-18.67 \mathrm{kcal} \mathrm{mol}^{-1}, \quad \Delta^{\mathrm{pt}} G=-18.54 \mathrm{kcal} \mathrm{mol}^{-1}, \quad \Delta^{\mathrm{pt}} H=$ $\left.-18.25 \mathrm{kcal} \mathrm{mol}^{-1}, \Delta^{\mathrm{pt}} S=0.98 \mathrm{cal} /(\mathrm{mol} \mathrm{K})\right)$ must be taken into account. Evaporation rates calculated according to Eqs. (2)-(4) are listed in Tables 2 and 3.

A comparison of computational and experimental free energy changes of ammonia addition to form small positively charged ammonia-containing clusters is presented in Table 4. The differences between the computational and experimental values are around $1 \mathrm{kcal} \mathrm{mol}^{-1}$ or less, but for larger clusters the error in the computational free energies may be larger. Computational proton affinities of $\mathrm{HSO}_{4}^{-},\left(\mathrm{CH}_{3}\right)_{2} \mathrm{NH}$ and $\mathrm{NH}_{3}$ are all within $2 \mathrm{kcal} \mathrm{mol}^{-1}$ of the NIST (2012) standard reference database values (Hunter and Lias, 1998; Wang et al., 2000) (Table 5). No systematic and fully reliable benchmarks for Gibbs free energy changes are currently available in the literature for the types of cluster studied here (Herb et al., 2011), but based on the proton affinity comparisons, the above-mentioned ammonia addition energies, and the method comparisons by Ortega et al. (2012), we estimate that the errors in free energy changes for adding a molecule to a cluster are below $2 \mathrm{kcal} \mathrm{mol}^{-1}$. This corresponds to an error below two orders of magnitude in the evaporation rates. Finally, there remains the possibility that we have not found the global minimum energy structure for some cluster, which can lead to an error of even several $\mathrm{kcal} \mathrm{mol}^{-1}$.

\subsection{Base substitutions}

According to our simulations, the basic mechanism of the base substitution (see Fig. 1 for the one-acid case) is as follows: when a DMA molecule collides with an ammonia containing cluster and sticks to it, the number of base molecules 
Table 2. Formation free energies $\left(\mathrm{kcal} \mathrm{mol}^{-1}\right)$ and monomer evaporation rates $\left(\mathrm{s}^{-1}\right)$ of charged sulfuric acid (SA) - ammonia $(\mathrm{Am})-$ dimethylamine (DMA) clusters.

\begin{tabular}{|c|c|c|c|c|c|c|}
\hline & $\Delta E_{\text {elec }}$ & $\Delta G$ & $\Delta H$ & $\gamma_{\mathrm{SA}}$ & rDMA & $\gamma \mathrm{Am}$ \\
\hline$[\mathrm{SA} \cdot \mathrm{Am}]^{+}$ & -20.90 & -15.60 & -20.13 & $1.86 \times 10^{-1}$ & & \\
\hline$[\mathrm{SA} \cdot \mathrm{DMA}]^{+}$ & -19.29 & -10.83 & -18.19 & $1.01 \times 10^{3}$ & & \\
\hline$\left[(\mathrm{SA})_{2} \cdot \mathrm{Am}\right]^{+}$ & -47.43 & -26.87 & -45.38 & $1.76 \times 10^{2}$ & & \\
\hline$\left[(\mathrm{SA})_{2} \cdot \mathrm{DMA}\right]^{+}$ & -43.75 & -22.89 & -41.46 & $4.70 \times 10^{1}$ & & \\
\hline$\left[(\mathrm{Am})_{2}\right]+$ & -26.75 & -20.59 & -26.44 & & & $3.45 \times 10^{-5}$ \\
\hline$[\mathrm{DMA} \cdot \mathrm{Am}]^{+}$ & -22.13 & -13.79 & -20.87 & & $8.48 \times 10^{-14}$ & $6.24 \times 10^{0}$ \\
\hline$\left[(\mathrm{DMA})_{2}\right]+$ & -26.23 & -16.32 & -25.53 & & $8.21 \times 10^{-2}$ & \\
\hline$\left[\mathrm{SA} \cdot(\mathrm{Am})_{2}\right]^{+}$ & -57.24 & -37.54 & -54.16 & $1.49 \times 10^{-2}$ & & $2.76 \times 10^{-6}$ \\
\hline$[\mathrm{SA} \cdot \mathrm{DMA} \cdot \mathrm{Am}]^{+}$ & -52.72 & -31.78 & -49.26 & $2.42 \times 10^{-3}$ & $1.10 \times 10^{-15}$ & $1.50 \times 10^{-5}$ \\
\hline$\left[\mathrm{SA} \cdot(\mathrm{DMA})_{2}\right]^{+}$ & -65.60 & -44.58 & -61.47 & $6.86 \times 10^{-11}$ & $5.60 \times 10^{-15}$ & \\
\hline$\left[(\mathrm{SA})_{2} \cdot(\mathrm{Am})_{2}\right]^{+}$ & -84.60 & -52.01 & -80.48 & $7.74 \times 10^{-1}$ & & $1.21 \times 10^{-8}$ \\
\hline$\left[(\mathrm{SA})_{2} \cdot \mathrm{DMA} \cdot \mathrm{Am}\right]^{+}$ & -80.24 & -46.59 & -75.93 & $4.30 \times 10^{-1}$ & $2.69 \times 10^{-18}$ & $1.37 \times 10^{-7}$ \\
\hline$\left[(\mathrm{SA})_{2} \cdot(\mathrm{DMA})_{2}\right]^{+}$ & -94.36 & -58.85 & -89.29 & $1.08 \times 10^{0}$ & $1.28 \times 10^{-16}$ & \\
\hline$\left[\mathrm{SA} \cdot \mathrm{DMA} \cdot(\mathrm{Am})_{2}\right]^{+}$ & -72.16 & -41.21 & -67.75 & & $1.62 \times 10^{-6}$ & $4.04 \times 10^{3}$ \\
\hline$[\mathrm{SA} \cdot(\mathrm{DMA}) 2 \cdot \mathrm{Am}]^{+}$ & -84.26 & -50.73 & -78.89 & & $3.87 \times 10^{-4}$ & $1.04 \times 10^{6}$ \\
\hline$\left[(\mathrm{SA})_{2} \cdot(\mathrm{Am})_{3}\right]^{+}$ & -119.34 & -72.94 & -111.92 & $1.88 \times 10^{-8}$ & & $1.47 \times 10^{-5}$ \\
\hline$\left[(\mathrm{SA})_{2} \cdot \mathrm{DMA} \cdot(\mathrm{Am})_{2}\right]^{+}$ & -115.64 & -67.33 & -108.11 & $2.11 \times 10^{-9}$ & $4.40 \times 10^{-15}$ & $1.98 \times 10^{-5}$ \\
\hline$\left[(\mathrm{SA})_{2} \cdot(\mathrm{DMA})_{2} \cdot \mathrm{Am}\right]^{+}$ & -129.23 & -78.68 & -120.88 & $9.50 \times 10^{-11}$ & $8.55 \times 10^{-14}$ & $9.18 \times 10^{-5}$ \\
\hline$\left[(\mathrm{SA})_{2} \cdot(\mathrm{DMA})_{3}\right]^{+}$ & -137.73 & -88.18 & -128.94 & & $8.99 \times 10^{-12}$ & \\
\hline$\left[(\mathrm{SA})_{2} \cdot \mathrm{DMA} \cdot(\mathrm{Am})_{3}\right]^{+}$ & -132.06 & -73.04 & -123.15 & & $6.36 \times 10^{-4}$ & $2.12 \times 10^{6}$ \\
\hline$\left[(\mathrm{SA})_{2} \cdot(\mathrm{DMA})_{2} \cdot(\mathrm{Am})_{2}\right]^{+}$ & -145.57 & -84.27 & -136.00 & & $1.10 \times 10^{-2}$ & $2.55 \times 10^{6}$ \\
\hline$\left[(\mathrm{SA})_{2} \cdot(\mathrm{DMA})_{3} \cdot \mathrm{Am}\right]^{+}$ & -160.38 & -97.67 & -149.94 & & $3.50 \times 10^{-4}$ & $3.58 \times 10^{3}$ \\
\hline$\left[(\mathrm{Am})_{3}\right]^{+}$ & -46.54 & -29.38 & -43.94 & & & $1.56 \times 10^{4}$ \\
\hline$\left[\mathrm{SA} \cdot(\mathrm{Am})_{3}\right]^{+}$ & -77.48 & -48.07 & -73.76 & $8.35 \times 10^{-4}$ & & $7.20 \times 10^{2}$ \\
\hline$\left[(\mathrm{SA})_{2} \cdot(\mathrm{Am})_{4}\right]^{+}$ & -138.34 & -81.77 & -130.13 & & & $1.24 \times 10^{4}$ \\
\hline
\end{tabular}

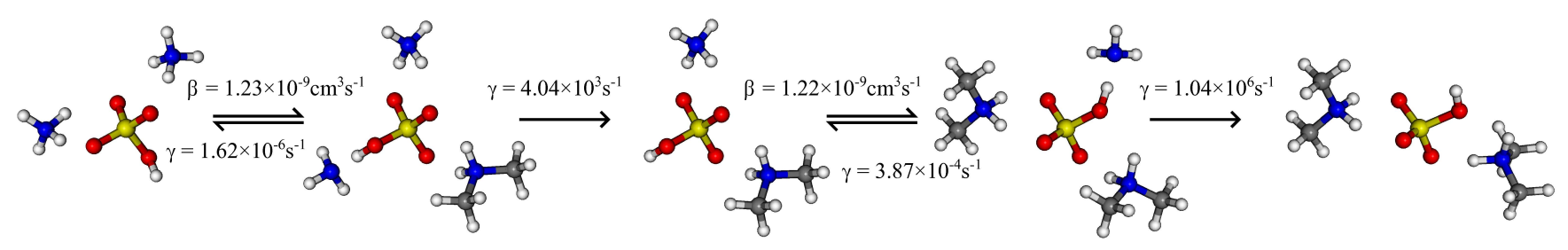

Fig. 1. Substitution of ammonia by DMA in a positively charged one acid - two base cluster.

compared to acids grows and the cluster becomes unstable. The evaporation rate of ammonia from the cluster is typically several orders of magnitude larger than that of DMA, and an ammonia molecule will be evaporated in a fraction of a second. Consequently, the cluster stabilizes, and remains as it is until another molecule sticks to it. The overall mech- anism can, however, be more complex, as the clusters may also evaporate or grow depending on the monomer concentrations. 
Table 3. Formation free energies $\left(\mathrm{kcal} \mathrm{mol}^{-1}\right)$ and monomer evaporation rates $\left(\mathrm{s}^{-1}\right)$ of neutral sulfuric acid (SA) - ammonia $($ Am) dimethylamine (DMA) clusters.

\begin{tabular}{l|rrr|rrr}
\hline & $\Delta E_{\text {elec }}$ & $\Delta G$ & $\Delta H$ & $\gamma_{\text {SA }}$ & $\gamma_{\text {DMA }}$ & $\gamma_{\text {Am }}$ \\
\hline $\mathrm{SA} \cdot \mathrm{DMA} \cdot \mathrm{Am}$ & -42.01 & -18.49 & -37.65 & & $1.45 \times 10^{2}$ & $8.24 \times 10^{7}$ \\
$(\mathrm{SA})_{2} \cdot \mathrm{DMA} \cdot \mathrm{Am}$ & -82.14 & -43.88 & -75.6 & $2.79 \times 10^{-9}$ & $2.99 \times 10^{-5}$ & $4.27 \times 10^{3}$ \\
$(\mathrm{SA})_{3} \cdot \mathrm{DMA} \cdot \mathrm{Am}$ & -112.68 & -60.65 & -104.26 & $6.06 \times 10^{-3}$ & $4.37 \times 10^{-10}$ & $7.07 \times 10^{0}$ \\
& & & & & & \\
$\mathrm{SA} \cdot \mathrm{DMA} \cdot(\mathrm{Am})_{2}$ & -49.96 & -14.98 & -44.34 & & $2.08 \times 10^{8}$ & $6.36 \times 10^{12}$ \\
$(\mathrm{SA})_{2} \cdot \mathrm{DMA} \cdot(\mathrm{Am})_{2}$ & -100.05 & -46.44 & -92.17 & $1.07 \times 10^{-13}$ & $4.02 \times 10^{0}$ & $2.46 \times 10^{8}$ \\
$(\mathrm{SA})_{3} \cdot \mathrm{DMA} \cdot(\mathrm{Am})_{2}$ & -140.28 & -73.97 & -129.25 & $8.41 \times 10^{-11}$ & $1.75 \times 10^{-8}$ & $3.45 \times 10^{0}$ \\
& & & & & & \\
$\mathrm{SA} \cdot(\mathrm{DMA})_{2} \cdot \mathrm{Am}$ & -59.06 & -22.57 & -53.14 & & $1.63 \times 10^{7}$ & $3.77 \times 10^{8}$ \\
$(\mathrm{SA})_{2} \cdot(\mathrm{DMA})_{2} \cdot \mathrm{Am}$ & -109.67 & -58.24 & -100.73 & $8.96 \times 10^{-17}$ & $5.11 \times 10^{-1}$ & $5.82 \times 10^{8}$ \\
$(\mathrm{SA})_{3} \cdot(\mathrm{DMA})_{2} \cdot \mathrm{Am}$ & -147.53 & -80.56 & -136.06 & $5.67 \times 10^{-7}$ & $4.68 \times 10^{-5}$ & $3.67 \times 10^{0}$ \\
\hline
\end{tabular}

Table 4. Experimental (Froyd and Lovejoy, 2012) and computational (B3LYP/CBSB7//RI-CC2/aug-cc-pV(T+d)Z) $\Delta G$ values $\left(\mathrm{kcal} \mathrm{mol}^{-1}\right.$ ) for ammonia addition.

\begin{tabular}{lrrr}
\hline & exp. $\Delta G$ & comp. $\Delta G$ & difference \\
\hline$\left[(\mathrm{Am})_{2}\right]^{+}+\mathrm{Am} \rightarrow\left[(\mathrm{Am})_{3}\right]^{+}$ & -9.92 & -8.79 & 1.13 \\
{$\left[\mathrm{SA} \cdot(\mathrm{Am})_{2}\right]^{+}+\mathrm{Am} \rightarrow\left[\mathrm{SA} \cdot(\mathrm{Am})_{3}\right]^{+}$} & -9.95 & -10.53 & -0.58 \\
{$\left[(\mathrm{SA})_{2} \cdot(\mathrm{Am})_{3}\right]^{+}+\mathrm{Am} \rightarrow\left[(\mathrm{SA})_{2} \cdot(\mathrm{Am})_{4}\right]^{+}$} & -8.17 & -8.83 & -0.66 \\
\hline
\end{tabular}

Table 5. Comparison of computational (B3LYP/CBSB7//RI$\mathrm{CC} 2 /$ aug-cc-pV $(\mathrm{T}+\mathrm{d}) \mathrm{Z})$ proton affinities $\left(\mathrm{kcal} \mathrm{mol}^{-1}\right)$ to the NIST (2012) standard reference values.

\begin{tabular}{llll}
\hline & reference & this study & difference \\
\hline $\mathrm{HSO}_{4}^{-}$ & $309.6^{\mathrm{a}}$ & 308.63 & -1.0 \\
$\left(\mathrm{CH}_{3}\right)_{2} \mathrm{NH}$ & $222.2^{\mathrm{b}}$ & 220.38 & -1.8 \\
$\mathrm{NH}_{3}$ & $204.0^{\mathrm{b}}$ & 202.13 & -1.9 \\
\hline
\end{tabular}

${ }^{a}$ Wang et al. (2000), ${ }^{\mathrm{b}}$ Hunter and Lias (1998).

\subsubsection{Positive clusters}

To test our quantum chemistry results, we have applied our kinetic model to the system studied experimentally by Bzdek et al. (2010a) using Fourier transform ion cyclotron resonance mass spectroscopy. A small concentration $\left(1 \mathrm{~cm}^{-3}\right.$ in our study) of $\left[(\mathrm{SA})_{2} \cdot(\mathrm{Am})_{3}\right]^{+}$clusters was let to react with neutral DMA gas at a pressure of $1.2 \times 10^{-8}$ Torr (same pressure as in the experiment), and the concentrations of different clusters were monitored as a function of time. A comparison of our results and the results by Bzdek et al. (2010a) is presented in Fig. 2.

The results agree very well, and the small differences are mainly due to the simple treatment of collision rates and sticking factors used in our study. We also get the same result as Bzdek et al. that $\left[(\mathrm{SA})_{2} \cdot(\mathrm{DMA})_{3}\right]^{+}$and $\left[\mathrm{SA} \cdot(\mathrm{DMA})_{2}\right]^{+}$ clusters do not undergo any base substitutions when subjected to pure ammonia gas at any pressure.

In the case of positive ions, the clusters where the number of base molecules is larger by one than the number of acids seem to be by far more stable than any other clusters. The reaction mechanism of a $\left[(\mathrm{SA})_{2} \cdot(\mathrm{Am})_{3}\right]^{+}$cluster in DMA gas is similar for DMA concentrations ranging from $5 \times 10^{-9}$ Torr to $2 \times 10^{-6}$ Torr,

$$
\begin{aligned}
& {\left[(\mathrm{SA})_{2} \cdot(\mathrm{Am})_{3}\right]^{+}+\mathrm{DMA} \rightarrow\left[(\mathrm{SA})_{2} \cdot \mathrm{DMA} \cdot(\mathrm{Am})_{3}\right]^{+}} \\
& \quad \rightarrow\left[(\mathrm{SA})_{2} \cdot \mathrm{DMA} \cdot(\mathrm{Am})_{2}\right]^{+}+\mathrm{Am} \\
& \quad\left[(\mathrm{SA})_{2} \cdot \mathrm{DMA} \cdot(\mathrm{Am})_{2}\right]^{+}+\mathrm{DMA} \rightarrow\left[(\mathrm{SA})_{2} \cdot(\mathrm{DMA})_{2} \cdot(\mathrm{Am})_{2}\right]^{+} \\
& \quad \rightarrow\left[(\mathrm{SA})_{2} \cdot(\mathrm{DMA})_{2} \cdot \mathrm{Am}\right]^{+}+\mathrm{Am} \\
& {\left[(\mathrm{SA})_{2} \cdot(\mathrm{DMA})_{2} \cdot \mathrm{Am}\right]^{+}+\mathrm{DMA} \rightarrow\left[(\mathrm{SA})_{2} \cdot(\mathrm{DMA})_{3} \cdot \mathrm{Am}\right]^{+}} \\
& \quad \rightarrow\left[(\mathrm{SA})_{2} \cdot(\mathrm{DMA})_{3}\right]^{+}+\mathrm{Am},
\end{aligned}
$$

where the second step of each reaction happens several orders of magnitude faster than the first. In lower pressures, the clusters start to evaporate slowly, first becoming $\left[\mathrm{SA} \cdot(\mathrm{DMA})_{2}\right]^{+}$clusters and in even lower pressures single $\left(\mathrm{CH}_{3}\right)_{2} \mathrm{NH}_{2}^{+}$ions.

In the atmosphere, the sulfuric acid concentration is of the order of $10^{6} \mathrm{~cm}^{-3}$ or higher (Eisele and Tanner, 1993), the DMA concentration ranges approximately from $10^{7}$ to $10^{10} \mathrm{~cm}^{-3}$ (Ge et al., 2011) and the ammonia concentration is typically between $10^{9}$ and $10^{12} \mathrm{~cm}^{-3}$ (Ge et al., 2011). In these conditions, the collision rates of acid and base 


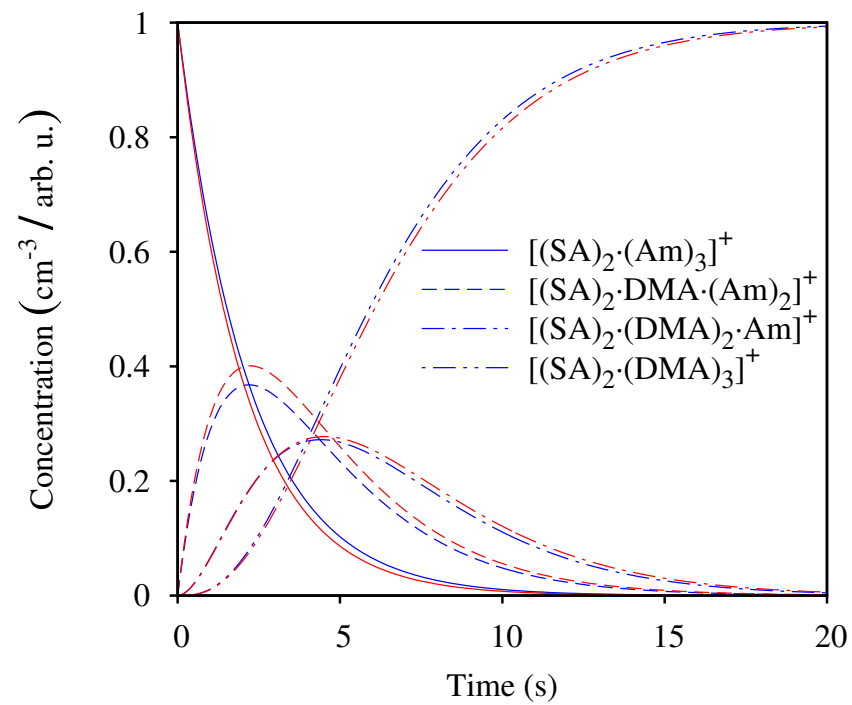

Fig. 2. Reaction of $\left[(\mathrm{SA})_{2} \cdot(\mathrm{Am})_{3}\right]^{+}$clusters with DMA gas at a pressure of $1.2 \times 10^{-8}$ Torr. Blue: modeled concentrations in $\mathrm{cm}^{-3}$, red: experimentally observed relative concentrations (Bzdek et al., 2010a).

molecules with positively charged clusters would be higher than the evaporation rates of many clusters. In addition to the base substitution process discussed in this study, the clusters would then be able to grow.

\subsubsection{Neutral clusters}

The first difference to be noted between charged and neutral clusters is that the collision coefficients of the smallest clusters are nearly one order of magnitude smaller for neutrals, meaning that the monomer concentrations must be ten times higher to produce comparable collision rates for clusters of the same size. Further, the numbers of acid and base molecules in especially stable clusters do not behave as systematically as for positive clusters.

In Figs. 3 and 4, we present two hypothetical experiments analogous to that in Fig. 2 but with neutral clusters. These do not correspond to a real atmosphere-like situation, but simply provide an example showing the dangers of drawing conclusions about neutral systems directly based on charged cluster measurements.

In Fig. 3, neutral $(\mathrm{SA})_{2} \cdot \mathrm{Am}$ clusters (concentration $1 \mathrm{~cm}^{-3}$ ) are let to react with DMA gas at a pressure of $10^{-6}$ Torr, which is the lowest pressure where the clusters do not evaporate before the base exchange can happen. Similarly to the positive case, the ammonia molecule is replaced by a DMA at collision rate. Then, as opposed to the charged case, a second DMA molecule colliding with the cluster will also be attached to it, leading to the formation of a $(\mathrm{SA})_{2} \cdot(\mathrm{DMA})_{2}$ cluster. The $(\mathrm{SA})_{2} \cdot(\mathrm{Am})_{2}$ cluster, on the other hand, is not stable and would lose the second ammonia molecule with an evaporation rate of $1.8 \times 10^{3} \mathrm{~s}^{-1}$. A

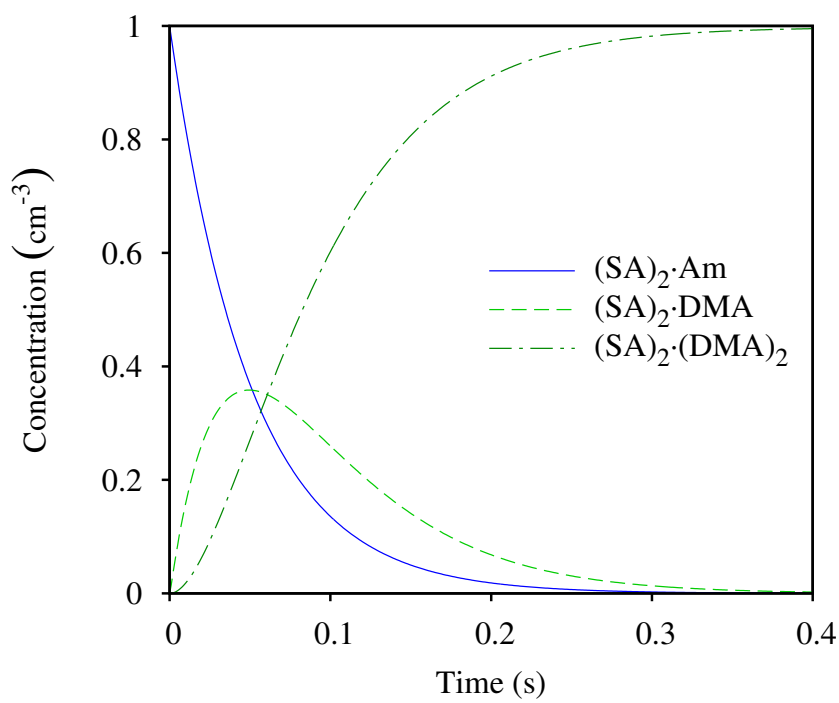

Fig. 3. Reaction of $(\mathrm{SA})_{2} \cdot$ Am clusters with DMA gas at a pressure of $10^{-6}$ Torr.

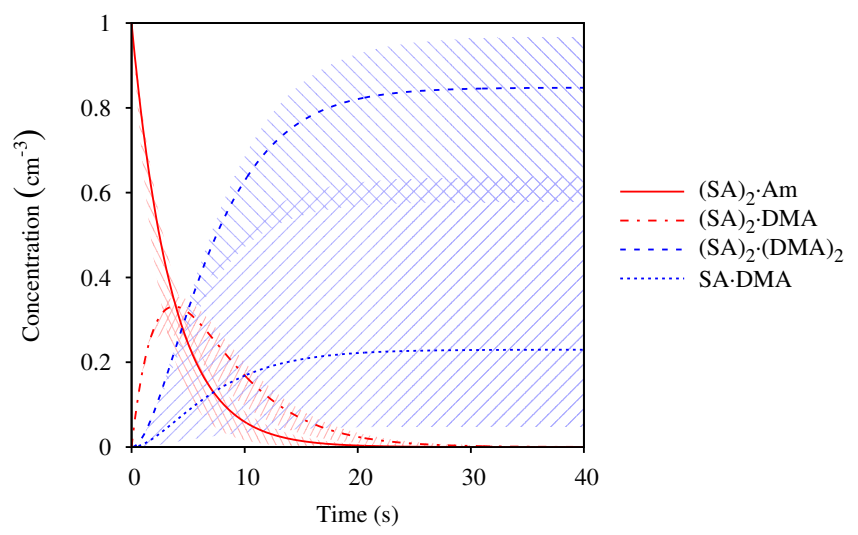

Fig. 4. Reaction of $(\mathrm{SA})_{2} \cdot$ Am clusters with DMA gas at a pressure of $1.2 \times 10^{-8}$ Torr. The sensitivity of the dynamics to cluster formation energies is seen by lowering the Gibbs free energy of one species at a time by $1 \mathrm{kcal} \mathrm{mol}^{-1}$ and rerunning the simulation (shaded area).

similar asymmetry between the different bases was also observed experimentally by Bzdek et al. (2010b) for positive clusters - but only for clusters with at least 3 acids and 4 bases, and even then the uptake coefficient of the additional DMA molecule was very small. This difference can at least partly be explained by noting that the positive clusters have an excess proton which effectively turns one base molecule into its conjugate acid.

Figure 4 presents a similar simulation but with DMA pressure $1.2 \times 10^{-8}$ Torr as in the experimental study with charged clusters. Here evaporation competes with substitution, and the sensitivity of the model to the accuracy of energies becomes apparent. Since the free energies only appear in energy differences between colliding species and 
collision products, absolute errors related to the quantum chemistry methods mostly cancel out. We have roughly estimated the effect of errors in free energy differences on the modeled concentrations by lowering the Gibbs free energy of one species at a time by $1 \mathrm{kcal} \mathrm{mol}^{-1}$ (corresponding to a factor of 5.4 in evaporation rates) and rerunning the simulation. This provides some useful information about the sensitivity of the model to the energies of different clusters. The largest uncertainty in this particular system results from the relative stabilities of the $(\mathrm{SA})_{2} \cdot \mathrm{Am}$ and $(\mathrm{SA})_{2}$ clusters and hence the evaporation rate of the initial cluster. Once an ammonia molecule has evaporated, the remaining sulfuric acid dimer will break up and a fraction of the free sulfuric acid will form SA - DMA clusters. The final partitioning between these one-acid species depends on the formation energy of the SA. DMA clusters, but this is a minor error source compared to the evaporation rate of the initial cluster. The concentrations of the short-lived species $(\mathrm{SA})_{2} \cdot \mathrm{Am}$ and $(\mathrm{SA})_{2} \cdot$ DMA depend slightly on the evaporation rate of ammonia from the initial cluster, but they tend to zero in any case.

In general, if a cluster is extremely stable or if it is extremely unstable with respect to one evaporation pathway, even an error of one or two orders of magnitude in its evaporation rates, due to an error of two or three $\mathrm{kcal} \mathrm{mol}^{-1}$ in the corresponding free energy differences, is unlikely to affect the overall process. However, if a cluster can participate in different collision and evaporation processes with similar rates, the accuracy of the free energies can be crucial.

In the atmosphere, the concentrations of sulfuric acid and DMA are large enough to enable the formation and growth of clusters, though other molecules (e.g. organic acids) are also likely to be involved in growth processes, and may dominate above some particle size. Water vapor is present at a much higher concentration, and will probably be somehow involved. On one hand it stabilizes the clusters, but on the other hand it also competes with the bases, so the overall effect is uncertain and will have to be studied in detail in the future. Further, the concentrations of small clusters may become comparable to the monomer concentrations, and cluster-cluster collisions can no longer be neglected. For some large clusters, splitting into two clusters can also be more favorable than evaporation of single molecules (Ortega et al., 2012).

\section{Conclusions}

We have used a multi-step quantum chemistry method to calculate free energies of positively charged and neutral sulfuric acid - ammonia - dimethylamine clusters. These have been used to study the kinetics of the substitution of ammonia by DMA. In the charged case, we have compared our results with experimental observations and found a very good agreement.
Our results show that there are some major differences between the charged and neutral systems. For neutrals, collisions occur less frequently, and on the other hand the clusters are not as strongly bound and evaporate faster. The composition of the most stable clusters is different in the two cases, because the positive clusters have an excess proton, and the protonated base molecule acts effectively as an acid. Some key features, however, are similar in neutral and charged clusters. Both ammonia and DMA stabilize sulfuric acid clusters significantly, but the effect is even stronger for DMA. All ammonia molecules in small sulfuric acid clusters will be replaced by DMA at collision frequency.

In the atmosphere, the concentration of ammonia is typically a few orders of magnitude larger than that of DMA, and sulfuric acid therefore collides more frequently with ammonia. Due to the extremely effective substitution of DMA for ammonia, the vast majority of sub-nanometer sulfuric acid clusters in the atmosphere are, however, likely to contain DMA.

\section{Supplementary material related to this article is available online at: http://www.atmos-chem-phys.net/12/ 3591/2012/acp-12-3591-2012-supplement.pdf.}

Acknowledgements. We thank the Academy of Finland (Project number 1127372, Center of Excellence program project number 1118615, LASTU program project number 135054) and ERC projects 257360-MOCAPAF and 27463-ATMNUCLE for funding, and CSC - IT Center for Science in Espoo, Finland, for computing time.

Edited by: F. Yu

\section{References}

Ahlrichs, R., Bär, M., Häser, J., Horn, H., and Kölmel, C.: Electronic structure calculations on workstation computers: The program system TURBOMOLE, Chem. Phys. Lett., 162, 165-169, 1989.

Becke, A. D.: Density-functional thermochemistry. III. The role of exact exchange, J. Chem. Phys., 98, 5648-5652, 1993.

Bzdek, B. R., Ridge, D. P., and Johnston, M. V.: Amine exchange into ammonium bisulfate and ammonium nitrate nuclei, Atmos. Chem. Phys., 10, 3495-3503, doi:10.5194/acp-10-3495-2010, 2010.a.

Bzdek, B. R., Ridge, D. P., and Johnston, M. V.: SizeDependent Reactions of Ammonium Bisulfate Clusters with Dimethylamine, J. Phys. Chem. A, 114, 11638-11644, doi:10.1021/jp106363m, 2010b.

Dunning, Jr, T. H., Peterson, K. A., and Wilson, A. K.: Gaussian basis sets for use in correlated molecular calculations. X. The atoms aluminum through argon revisited, J. Chem. Phys., 114, 9244-9253, 2001.

Eisele, F. and Tanner, D.: Measurement of the gas phase concentration of $\mathrm{H}_{2} \mathrm{SO}_{4}$ and methane sulfonic acid and estimates of 
$\mathrm{H}_{2} \mathrm{SO}^{4}$ production and loss in the atmosphere, J. Geophys. Res., 98, 9001-9010, 1993.

Frisch, M. J., Trucks, G. W., Schlegel, H. B., Scuseria, G. E., Robb, M. A., Cheeseman, J. R., Scalmani, G., Barone, V., Mennucci, B., Petersson, G. A., Nakatsuji, H., Caricato, M., Li, X., Hratchian, H. P., Izmaylov, A. F., Bloino, J., Zheng, G., Sonnenberg, J. L., Hada, M., Ehara, M., Toyota, K., Fukuda, R., Hasegawa, J., Ishida, M., Nakajima, T., Honda, Y., Kitao, O., Nakai, H., Vreven, T., Montgomery, Jr, J. A. J. E. P., Ogliaro, F., Bearpark, M., Heyd, J. J., Brothers, E., Kudin, K. N., Staroverov, V. N., Kobayashi, R., Normand, J., Raghavachari, K., Rendell, A., Burant, J. C., Iyengar, S. S., Tomasi, J., Cossi, M., Rega, N., Millam, J. M., Klene, M., Knox, J. E., Cross, J. B., Bakken, V., Adamo, C., Jaramillo, J., Gomperts, R., Stratmann, R. E., Yazyev, O., Austin, A. J., Cammi, R., Pomelli, C., Ochterski, J. W., Martin, R. L., Morokuma, K., Zakrzewski, V. G., Voth, G. A., Salvador, P., Dannenberg, J. J., Dapprich, S., Daniels, A. D., Farkas, O., Foresman, J. B., Ortiz, J. V., Cioslowski, J., and Fox, D. J.: Gaussian 09, Revision A.01, Gaussian, Inc., Wallingford CT, 2009.

Froyd, K. and Lovejoy, E.: Bond Energies and Structures of Ammonia - Sulfuric Acid Positive Cluster Ions, J. Phys. Chem. A, doi:10.1021/jp209908f, in press, 2012.

Ge, X., Wexler, A. S., and Clegg, S. L.: Atmospheric amines - Part I. A review, Atmos. Environ., 45, 524-546, doi:10.1016/j.atmosenv.2010.10.012, http://dx.doi.org/10.1016/ j.atmosenv.2010.10.012, 2011.

Hättig, C. and Weigend, F.: CC2 excitation energy calculations on large molecules using the resolution of the identity approximation, J. Chem. Phys., 113, 5154-5161, 2000.

Herb, J., Nadykto, A., and Yu, F.: Large ternary hydrogen-bonded pre-nucleation clusters in the Earth's atmosphere, Chem. Phys. Lett., 518, 7-14, 2011.

Hunter, E. P. and Lias, S. G.: Evaluated Gas Phase Basicities and Proton Affinities of Molecules: An Update., J. Phys. Chem. Ref. Data, 3, 413-656, 1998.

Junninen, H., Ehn, M., Petäjä, T., Luosujärvi, L., Kotiaho, T., Kostiainen, R., Rohner, U., Gonin, M., Fuhrer, K., Kulmala, M., and Worsnop, D. R.: A high-resolution mass spectrometer to measure atmospheric ion composition, Atmos. Meas. Tech., 3, 10391053, doi:10.5194/amt-3-1039-2010, 2010.

Kirkby, J., Curtius, J., Almeida, J., Dunne, E., Duplissy, J., Ehrhart, S., Franchin, A., Gagne, S., Ickes, L., Kurten, A., Kupc, A., Metzger, A., Riccobono, F., Rondo, L., Schobesberger, S., Tsagkogeorgas, G., Wimmer, D., Amorim, A., Bianchi, F., Breitenlechner, M., David, A., Dommen, J., Downard, A., Ehn, M., Flagan, R. C., Haider, S., Hansel, A., Hauser, D., Jud, W., Junninen, H., Kreissl, F., Kvashin, A., Laaksonen, A., Lehtipalo, K., Lima, J., Lovejoy, E. R., Makhmutov, V., Mathot, S., Mikkila, J., Minginette, P., Mogo, S., Nieminen, T., Onnela, A., Pereira, P., Petaja, T., Schnitzhofer, R., Seinfeld, J. H., Sipila, M., Stozhkov, Y., Stratmann, F., Tome, A., Vanhanen, J., Viisanen, Y., Vrtala, A., Wagner, P. E., Walther, H., Weingartner, E., Wex, H., Winkler, P. M., Carslaw, K. S., Worsnop, D. R., Baltensperger, U., and Kulmala, M.: Role of sulphuric acid, ammonia and galactic cosmic rays in atmospheric aerosol nucleation, Nature, 476, 429, doi:10.1038/nature10343, 2011.

Kuang, C., McMurry, P. H., McCormick, A. V., and Eisele, F. L.: Dependence of nucleation rates on sulfuric acid vapor concen- tration in diverse atmospheric locations, J. Geophys. Res., 113, D10209, doi:10.1029/2007JD009253, 2008.

Kulmala, M.: Dynamical atmospheric cluster model, Atmos. Res., 98, 201-206, doi:10.1016/j.atmosres.2010.03.022, http://dx.doi org/10.1016/j.atmosres.2010.03.022, 2010.

Kulmala, M., Riipinen, I., Sipilä, M., Manninen, H. E., Petäjä, T., Junninen, H., Maso, M. D., Mordas, G., Mirme, A., Vana, M., Hirsikko, A., Laakso, L., Harrison, R. M., Hanson, I., Leung, C., Lehtinen, K. E. J., and Kerminen, V.-M.: Toward direct measurement of atmospheric nucleation, Science, 318, 89-92, 2007.

Kurtén, T.: A Comment on Nadytko et al., "Amines in the Earth's Atmosphere: A Density Functional Theory Study of the Thermochemistry of Pre-Nucleation Clusters". Entropy 2011, 13, 554569, Entropy, 13, 915-923, doi:10.3390/e13040915, 2011.

Kurtén, T., Noppel, M., Vehkamäki, H., Salonen, M., and Kulmala, M.: Quantum chemical studies of hydrate formation of $\mathrm{H}_{2} \mathrm{SO}_{4}$ and $\mathrm{HSO}_{4}^{-}$, Boreal Environ. Res., 12, 431-453, $2007 \mathrm{a}$.

Kurtén, T., Torpo, L., Ding, C.-G., Vehkamäki, H., Sundberg, M. R., Laasonen, K., and Kulmala, M.: A density functional study on water-sulfuric acid-ammonia clusters and implications for atmospheric cluster formation, Geophys. Res., 112, D04210, doi:10.1029/2006JD007391, 2007b.

Kurtén, T., Loukonen, V., Vehkamäki, H., and Kulmala, M.: Amines are likely to enhance neutral and ion-induced sulfuric acid-water nucleation in the atmosphere more effectively than ammonia, Atmos. Chem. Phys., 8, 4095-4103, doi:10.5194/acp8-4095-2008, 2008.

Kurtén, T., Kuang, C., Gómez, P., McMurry, P. H., Vehkamäki, H., Ortega, I. K., Noppel, M., and Kulmala, M.: The role of cluster energy nonaccommodation in atmospheric sulfuric acid nucleation, J. Chem. Phys., 132, 024304, doi:10.1063/1.3291213, 2010.

Kurtén, T., Petäjä, T., Smith, J., Ortega, I. K., Sipilä, M., Junninen, H., Ehn, M., Vehkamäki, H., Mauldin, L., Worsnop, D. R., and Kulmala, M.: The effect of $\mathrm{H}_{2} \mathrm{SO}_{4}$ - amine clustering on chemical ionization mass spectrometry (CIMS) measurements of gas-phase sulfuric acid, Atmos. Chem. Phys., 11, 3007-3019, doi:10.5194/acp-11-3007-2011, 2011.

Lide, D. (Ed.): CRC Handbook of Chemistry and Physics, 91th Edition, CRC Press/Taylor and Francis, Boca Raton, FL, 2010.

Loukonen, V., Kurtén, T., Ortega, I. K., Vehkamäki, H., Pádua, A. A. H., Sellegri, K., and Kulmala, M.: Enhancing effect of dimethylamine in sulfuric acid nucleation in the presence of water - a computational study, Atmos. Chem. Phys., 10, 49614974, doi:10.5194/acp-10-4961-2010, 2010.

Manninen, H. E., Petäjä, T., Asmi, E., Riipinen, I., Nieminen, T., Mikkilä, J., Hõrrak, U., Mirme, A., Mirme, S., Laakso, L., Kerminen, V.-M., and Kulmala, M.: Long-term field measurements of charged and neutral clusters using Neutral cluster and Air Ion Spectrometer (NAIS), Boreal Environ. Res., 14, 591-605, 2009.

Maria, S., Russell, L., Gilles, M., and Myneni, S.: Organic Aerosol Growth Mechanisms and Their Climate-Forcing Implications, Science, 306, 1921-1924, 2004.

Merikanto, J., Spracklen, D. V., Mann, G. W., Pickering, S. J., and Carslaw, K. S.: Impact of nucleation on global CCN, Atmos. Chem. Phys., 9, 8601-8616, doi:10.5194/acp-9-8601-2009, 2009.

Metzger, A., Verheggen, B., Dommen, J., Duplissy, J., Prevot, A. S. H., Weingartner, E., Riipinen, I., Kulmala, M., Spracklen, 
D. V., Carslaw, K. S., and Baltensperger, U.: Evidence for the role of organics in aerosol particle formation under atmospheric conditions, P. Natl. Acad. Sci. USA, 107, 6646-6651, doi:10.1073/pnas.0911330107, 2010.

Montgomery, Jr, J. A., Frisch, M. J., Ochterski, J. W., and Petersson, G. A.: A complete basis set model chemistry. VI. Use of density functional geometries and frequencies, J. Chem. Phys., 110, 2822-2827, 1999.

Nadykto, A., Yu, F., Jakovleva, M., Herb, J., and Xu, Y.: Amines in the Earth's Atmosphere: A Density Functional Theory Study of the Thermochemistry of Pre-Nucleation Clusters, Entropy, 13, 554-569, 2011.

Nadykto, A. B. and Yu, F.: Uptake of neutral polar vapor molecules by charged clusters particles: Enhancement due to dipole-charge interaction, J. Geophys. Res., 108, 4717, doi:10.1029/2003JD003664, 2003.

Nadykto, A. B. and Yu, F.: Strong hydrogen bonding between atmospheric nucleation precursors and common organics, Chem. Phys. Lett., 435, 14-18, 2007.

NIST Chemistry WebBook, NIST Standard Reference Database Number 69, edited by: Linstrom, P. J. and Mallard, W. G., National Institute of Standards and Technology, Gaithersburg MD, 20899, 2012.

O’Dowd, C., Aalto, P., Hämeri, K., Kulmala, M., and Hoffmann, T.: Aerosol formation: Atmospheric particles from organic vapours, Nature, 416, 497-498, 2002a.

O’Dowd, C. D., Jimenez, J. L., Bahreini, R., Flagan, R. C., Seinfeld, J. H., Hämeri, K., Pirjola, L., Kulmala, M., Jennings, S. G., and Hoffmann, T.: Marine aerosol formation from biogenic iodine emissions, Nature, 417, 632, 2002b.

Ortega, I. K., Kurtén, T., Vehkamäki, H., and Kulmala, M.: The role of ammonia in sulfuric acid ion induced nucleation, Atmos. Chem. Phys., 8, 2859-2867, doi:10.5194/acp-8-2859-2008, 2008.

Ortega, I. K., Kupiainen, O., Kurtén, T., Olenius, T., Wilkman, O., McGrath, M. J., Loukonen, V., and Vehkamäki, H.: From quantum chemical formation free energies to evaporation rates, Atmos. Chem. Phys., 12, 225-235, doi:10.5194/acp-12-225-2012, 2012.

Sedo, G., Schultz, J., and Leopold, K. R.: Electric dipole moment of sulfuric acid from Fourier transform microwave spectroscopy, J. Mol. Spectrosc., 251, 4-8, doi:10.1016/j.jms.2007.09.016, 2008.
Shantz, N. C., Leaitch, W. R., and Caffrey, P. F.: Effect of organics of low solubility on the growth rate of cloud droplets, J. Geophys. Res., 108, 4168, doi:10.1029/2002JD002540, 2003.

Sihto, S.-L., Kulmala, M., Kerminen, V.-M., Dal Maso, M., Petäjä, T., Riipinen, I., Korhonen, H., Arnold, F., Janson, R., Boy, M., Laaksonen, A., and Lehtinen, K. E. J.: Atmospheric sulphuric acid and aerosol formation: implications from atmospheric measurements for nucleation and early growth mechanisms, Atmos. Chem. Phys., 6, 4079-4091, doi:10.5194/acp-6-4079-2006, 2006.

$\mathrm{Su}$, T. and Bowers, M. T.: Theory of ion-polar molecule collisions. Comparison with experimental charge transfer reactions of rare gas ions to geometric isomers of difluorobenzene and dichloroethylene, J. Chem. Phys., 58, 3027, doi:10.1063/1.1679615, 1973.

Torpo, L., Kurtén, T., Vehkamäki, H., Sundberg, M. R., Laasonen, K., and Kulmala, M.: The significant role of ammonia in atmospheric nanoclusters, J. Phys. Chem. A, 111, 10671-10674, 2007.

Vehkamäki, H.: Classical nucleation theory in multicomponent systems, Springer, Berlin, 2006.

Wang, X. B., Nicholas, J. B., and Wang, L. S.: Photoelectron spectroscopy and theoretical calculations of $\mathrm{SO}_{4}^{-}$and $\mathrm{HSO}_{4}^{-}$: Confirmation of high electron affnities of $\mathrm{SO} 4$ and $\mathrm{HSO} 4$, J. Phys. Chem. A, 104, 504-508, 2000.

Wave function, I.: Spartan 06 Windows, available at: http:// wavefun.com, 2006.

Xu, Y., Nadykto, A. B., Yu, F., Herb, J., and Wang, W.: Interaction between Common Organic Acids and Trace Nucleation Species in the Earth's Atmosphere, J. Phys. Chem. A, 114, 387396, 2010.

Zhang, R., Suh, I., Zhao, J., Zhang, D., Fortner, E. C., Tie, X., Molina, L. T., and Molina, M. J.: Atmospheric New Particle Formation Enhanced by Organic Acids, Science, 304, 1487-1490, 2004. 